ISSN 0258-7122

Bangladesh J. Agril. Res. 37(4): 617-624, December 2012

\title{
GENETIC DIVERSITY ANALYSIS OF PARENTAL LINES FOR HYBRID DEVELOPMENT IN RICE (Oryza sativa L.)
}

\author{
M. J. HASAN ${ }^{1}$, UMMA KULSUM ${ }^{2}$, M. M. H. RAHMAN ${ }^{2}$, \\ M. M. H. CHOWDHURY ${ }^{3}$ AND A. Z. M. K. A. CHOWDHURY ${ }^{4}$
}

\begin{abstract}
Genetic divergence of 40 parental lines comprising 30 restorer and 10 maintainer lines were studied through Mohalanobis's $\mathrm{D}^{2}$ and principal component analysis for eleven characters. Genotypes were grouped into five different clusters. Cluster $\mathrm{V}$ comprised maximum number of genotypes (thirteen) followed by cluster I and II. The inter-cluster distance was maximum between clusters I and V (13.495) indicating wide genetic diversity between these two clusters followed by the distance between cluster I and 11 (9.489), cluster IV, and cluster V (8.969) and cluster I and cluster III (8.039). The minimum inter-cluster distance was observed between cluster II and cluster III (3.034) followed by cluster 111 and cluster IV (3.834) and cluster II and cluster $\mathrm{V}$ (4.945) indicating that the genotypes of these clusters were genetically close. The intra cluster distance in the entire five clusters was more or less low which indicated that the genotypes within the same cluster were closely related. Among the characters panicle weight contributed most for divergence in the studied parental lines. Difference in cluster means existed for almost all the characters studied. Highest mean value for number of effective tillers (7.8), days to $50 \%$ flowering (95.5), panicles/m² (192.6), panicle weight (2.9), spikelet fertility (84.8), number of grains/panicle (177.8), days to maturity (123.6), and grain yield/plot (1065.5) were observed in cluster I indicated the parental lines fallen in this cluster having the genetic potentiality to contribute better for yield maximization of hybrid rice.
\end{abstract}

Keywords: Rice, parental lines, genetic divergence.

\section{Introduction}

Rice is the staple food and ranks first in production among cereals in Bangladesh. Although Bangladesh is now on the verge of attaining self sufficiency in cereal production, there is still a large gap between the production and demand. Today, rice has special position as a source of providing over $75 \%$ of Asian population and more than three billion of world population's meal which represents 50 to $80 \%$ of their daily calorie intake (Khush, 2005; Amirjani, 2011). Thus, there is need to produce more rice per unit area per unit time. Achieving self-sufficiency in rice production and maintaining price stability are important political objectives in countries where rice provides food security and generates

\footnotetext{
${ }^{1}$ Principal Seientifec Officer, Hybrid Rice, Bangladesh Agricultural Research Institute (BRRI), Gazipur, ${ }^{2}$ Seientific Officer, Hybrid Rice, BRRI, Gazipur, ${ }^{3}$ Senior Instructor, CERDI, Gazipur, ${ }^{4} \mathrm{R} \& D$ in Charge, GETCO Agro Vision, Bangladesh.
} 
employment and income for people (Hossain, 1995). Yuan (1998) reported that more than $50 \%$ of rice area in China is covered by hybrid rice. Expansion of hybrid rice cultivation area may be an effective and economic way to meet the future rice demands of growing population of Bangladesh. Hybrid rice technology offers considerable opportunity for Bangladesh to increase the productivity of rice. One of the limitations of this technology, however, is the need for cultivators to secure new seeds every season. Use of rice hybrids is getting popularity in Bangladesh day by day. It was started in 1998 with few tons and in the year 2008, the quantity rose to 11000 tons of which 2800 tons are locally produced (Faruque, 2009). The performance and heterosis of hybrids are associated with genetic divergence between their parental lines. The selection of parental lines plays a vital role in developing ideal combinations. Selection of suitable parental (CMS/maintainer and restorer) lines to develop heterotic combinations can be facilitated by determining genetic divergence among them. Very limited work has been done on analysis of the genetic divergence in rice in relation to hybrid rice breeding. Careful selection of maintainer and restorer lines on the basis of their genetic diversity may lead to the development of hybrids with higher yield potential than parents and standard check varieties (Julfiquar et al., 1985). Hybrid rice is considered as a viable alternative technology for breaking the present yield ceiling of modern varieties. Experience in China and outside China clearly indicates that hybrid rice technology offers a viable option to meet this challenge. Hybrid rice varieties have clearly shown a 1-1.5 t/ha yield advantage over semi-dwarf inbred high-yielding varieties in farmers' fields in China and other countries (Virmani and Kumar, 2004). If we are able to breed parental lines of hybrid rice in our own environment, it will suit more and perform better than exotic ones.

Thus keeping in view the above facts, present study was conducted to estimate the nature and magnitude of genetic divergence and characters contributing to the genetic divergence of 40 parental lines of hybrid rice. This study will help select more distantly related restorer as well as maintainer lines for using in crossing programme and ultimately help develop more heterotic hybrid rice varieties in local conditions.

\section{Materials and Method}

Forty parental lines were grown in a randomized complete block design with three replications at the experimental farm of Bangladesh Rice Research Institute, Gazipur during July to December 2010. The experimental site was at $24.00^{\circ} \mathrm{N}$ latitude and $90.25^{\circ} \mathrm{E}$ longitude with an elevation of 8.4 meter from the sea level. The whole experimental area was divided into three blocks, representing three replications. Adequate soil fertility was ensured by 
applying additional quantities of Urea- TSP-MP- Gypsum- $\mathrm{ZnSO}_{4}$ @ 150-100-70-60-10 kg/ha, respectively. Total TSP, MP, Gypsum, and $\mathrm{ZnSO}_{4}$ were applied in final land preparation. Total Urea was applied in three installments at 15 days after transplanting (DAT), 30 DAT, and 45 DAT. Twenty one days old seedlings of parental lines were transplanted in separate strips with spacing of $15 \times 15 \mathrm{~cm}$ between plants and $20 \times 20 \mathrm{~cm}$ between rows. Necessary intercultural operation was made during cropping period for proper growth and development of the plants. Data were collected from 10 randomly selected hills of each parental line on individual plant basis for plant height, number of effective tillers per hill, days to $50 \%$ flowering, flag leaf length, number of panicles $/ \mathrm{m}^{2}$, panicle weight, spikelet fertility, number of grains per panicles, days to maturity, 1000 grain weight and grain yield per plot. Mean data of each character was subjected to multivariate analysis viz, Principal Coordinate Analysis (PCO), Principal Component Analysis (PCA), Cluster Analysis, and Canonical Variate Analysis using GENSTAT 513 (Mahalanobis, 1936; Digby et al., 1989 and Jager et al., 1983).

\section{Results and Discussion}

The computations from distance matrix gave non-hierarchical clustering among 40 parental lines and grouped them into five clusters (Table 1). Cluster $\mathrm{V}$ contained the highest number of parental lines (thirteen) comprising of nine maintainer and four restorer lines followed by cluster I constituted by eight parental lines but all belonged to restorer lines. Cluster IV was composed of seven parental lines of which one maintainer (Gan46B) and rest six from restorer lines indicated that this maintainer line had genetic similarity with other restorer lines hence they fallen into same cluster. Cluster II and III constituted of seven and five parental lines, respectively, but all belonged to restorer lines. Iftekharuddaula et al. (2002) reported that the crosses involving the parents belonging to distinct clusters would offer prime scope in the development of high yielding irrigated rice.

Intra (bold) and inter cluster distances were presented in Table 2. The inter-cluster distances were larger than the intra cluster distances. Intracluster distances were estimated using the inter genotypic distance followed by Singh and Chaudhuary (1977).The inter-cluster distance was maximum between clusters I and V (13.459) indicated wide genetic diversity between these two clusters followed by the distance between cluster I and II (9.489), cluster IV and cluster V (8.969), and cluster I and cluster III (8.039). 
Table 1. Distribution of $\mathbf{4 0}$ parental lines of hybrid rice in different clusters.

\begin{tabular}{|c|c|c|c|}
\hline $\begin{array}{l}\text { Cluster } \\
\text { no. }\end{array}$ & $\begin{array}{r}\text { SL. No. of } \\
\text { parental lines }\end{array}$ & $\begin{array}{l}\text { No. of } \\
\text { parental } \\
\text { lines }\end{array}$ & Parental lines \\
\hline I & $\begin{array}{l}2,3,5,8,15 \\
27,28,30\end{array}$ & 8 & $\begin{array}{l}\text { BR168R, BR736R, BR6839-41-5-1R, M.H.63R, } \\
\text { 1R68011-15-1-12-3R, 1R72887-38-1-3-2R, } \\
\text { 1R72906-24- 1-3-IR, 1R69701-41-3-1 R }\end{array}$ \\
\hline II & $\begin{array}{l}7,11,13,17 \\
20,25,26\end{array}$ & 7 & $\begin{array}{l}\text { BR7011-37-1-2R, Wan3R, 1R7320-44-2-3-1R, } \\
\text { 1R73004-7-3-3-3R, 1R71 137-328-2-3-3-3-2R, } \\
\text { 1R44675R, 1R32809-26-3-3R }\end{array}$ \\
\hline III & $6,10,12,14,18$ & 5 & $\begin{array}{l}\text { BR7013-62-1-1R, Gui99R, IR40750R, } \\
\text { PSBRC82R, IR64R }\end{array}$ \\
\hline IV & $\begin{array}{l}1,4,16,23,24 \\
29,36\end{array}$ & 7 & $\begin{array}{l}\text { BR827R, BR6723-1-1-2R, 1R73004-107-3-3- } \\
\text { 2R, AjayaR, IR73013-95-1-3-2R, IR69702-3-2- } \\
\text { 3R, Gan46B }\end{array}$ \\
\hline V & $\begin{array}{l}9,19,21,22, \\
31,32,33,34 \\
35,37,38,39 \\
40\end{array}$ & 13 & $\begin{array}{l}\text { M.H.77R, IR46R, IR 73885-1-4-1-4-4-3-6R, } \\
\text { 1R69716-1- 1-5-IR, IR58025B, I132B, Jin23B, } \\
\text { IR78362B, D.ShanB, } \\
\text { BRRI3B, BRRI9B, IR75608B, IR77811B }\end{array}$ \\
\hline
\end{tabular}

On the basis of principal component axes I (PCA score 1) and II (PCA score II), a two dimension (Z I -Z2) scattered diagram of the 40 parental lines were constructed where the genotypes apparently distributed into five clusters (Fig. 1).

Table 2. Intra (Bold) and inter cluster distances $\left(D^{2}\right)$ for $\mathbf{4 0}$ parental lines of hybrid rice.

\begin{tabular}{cccccc}
\hline Cluster & I & II & III & IV & V \\
\hline I & $\mathbf{0 . 4 5 8}$ & 9.489 & 8.039 & 5.074 & 13.459 \\
II & & $\mathbf{0 . 3 6 2}$ & 3.034 & 4.997 & 4.945 \\
III & & & $\mathbf{0 . 4 8 9}$ & 3.834 & 6.420 \\
IV & & & & $\mathbf{0 . 5 3 7}$ & 8.969 \\
V & & & & & $\mathbf{0 . 7 1 8}$
\end{tabular}

The minimum inter-cluster distance was observed between cluster II and cluster III (3.034) followed by cluster III and cluster IV (3.834) and cluster II and cluster V (4.945) indicated that the genotypes of these clusters were genetically close. 


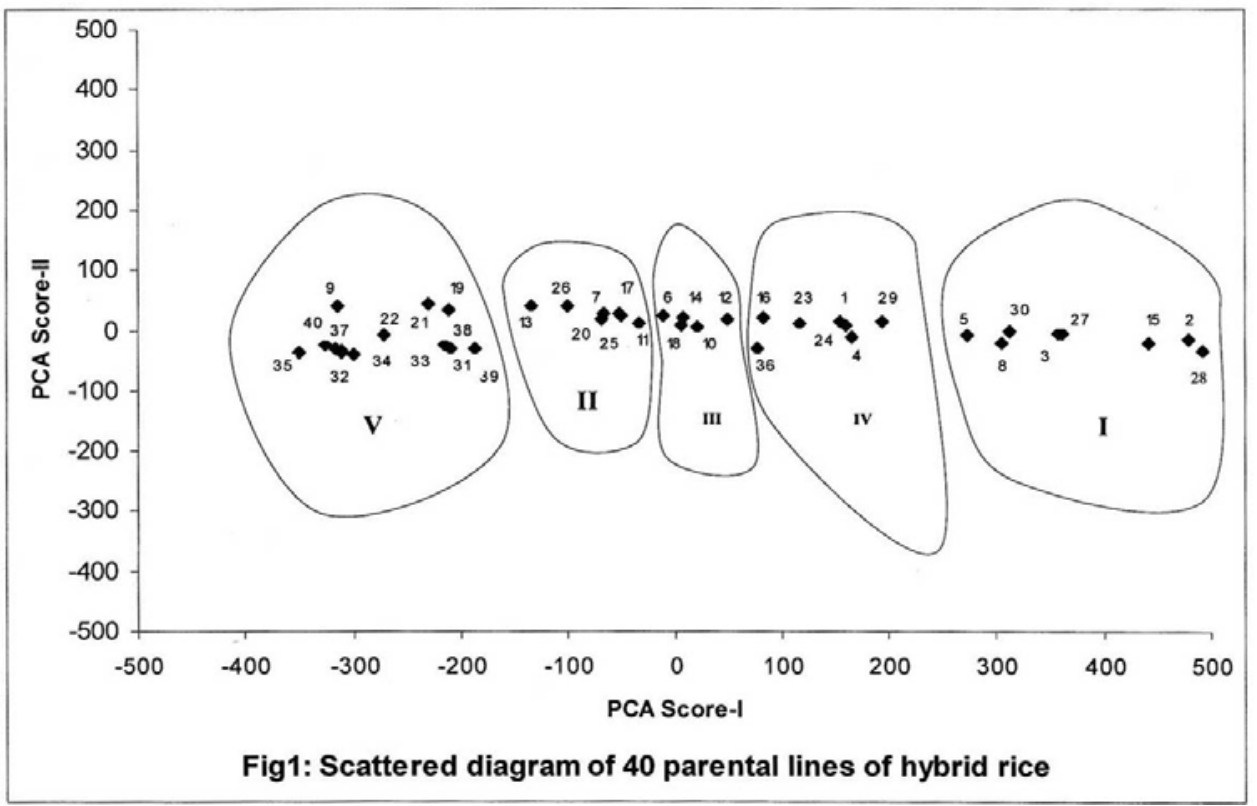

The selection of diverge genotype, from cluster would produce a broad spectrum of variability for morphological and quality traits studied which may enable further selection and improvement. The hybrid developed from the selected genotypes within the limits of compatibility of these clusters may produce high magnitude of heterosis. This would be rewarding in hybrid rice breeding programme. Sarawgi and Shrivastava (1996), Sarawgi and Rastogi (2000), Roy et al. (2002), and Naik et al. (2004) were in agreement with these findings. Cluster mean value of 11 different characters are shown in Table 3.

Table 3. Cluster mean values of different characters of $\mathbf{4 0}$ parental lines of hybrid rice.

\begin{tabular}{lccrcc}
\hline \multicolumn{1}{c}{ Characters } & I & I I & Ill & I V & V \\
\hline Plant height (cm) & 113.3 & 114.3 & 114 & 115.9 & 104.6 \\
Number of effective tillers & 7.8 & 6.4 & 7.2 & 7.0 & 5.0 \\
Days to 50\% flowering & 95.5 & 89.6 & 88.0 & 94.9 & 80.2 \\
Flag leaf length (cm) & 38.4 & 35.7 & 33.9 & 40.5 & 32.3 \\
Panicles/m & 192.6 & 159.1 & 179.8 & 173.4 & 151.5 \\
Panicle weight (g) & 2.9 & 2.5 & 2.0 & 2.9 & 2.6 \\
Spikelet fertility (\%) & 84.8 & 79.6 & 81.7 & 82.4 & 73.0 \\
Number of grains/panicle & 177.8 & 174.0 & 172.3 & 170.3 & 116.6 \\
Days to maturity (days) & 123.6 & 116.6 & 114.6 & 123.0 & 107.8 \\
1000-grain weight (g) & 24.2 & 26.4 & 21.4 & 22.3 & 23.5 \\
Grain yield/plot (g) & 1065.5 & 614.9 & 701.7 & 824.1 & 419.0 \\
\hline
\end{tabular}


Difference in cluster means existed for almost all the characters studied. Highest mean value for number of effective tillers, days to $50 \%$ flowering, panicles $/ \mathrm{m}^{2}$, panicle weight, spikelet fertility, number of grains/panicle, days to maturity, and grain yield/per plot were observed in cluster I indicated the parental lines fallen in this cluster having the genetic potentiality to contribute better for yield maximization of hybrid rice. Heavy panicle weight along with maximum flag leaf length and plant height bearing genotypes were gathered into cluster IV. Cluster V had the genotypes that showed lowest mean value for almost all the characters studied indicating selection of parental lines from these cluster for future hybrid rice breeding programme have no positive impact except for earliness.

Relative contribution of different characters towards divergence is presented in Table 4 . Vector- 1 and Vector-2 value were obtained from PCA.

Table 4. Relative contributions of different characters of $\mathbf{4 0}$ parental lines to the total divergence.

\begin{tabular}{lcr}
\hline \multicolumn{1}{c}{ Characters } & Vector-1 & \multicolumn{1}{c}{ Vector-2 } \\
\hline Plant height (cm) & 0.01642 & 0.01536 \\
Number of effective tillers & 0.50021 & -0.32250 \\
Days to 50\% flowering & -0.13154 & 0.02581 \\
Flag leaf length (cm) & 0.08549 & 0.05750 \\
Panicles $/ \mathrm{m}^{2}$ & -0.01170 & 0.00787 \\
Panicle weight (g) & 0.15575 & 0.15605 \\
Spikelet fertility (\%) & 0.01878 & 0.09782 \\
No. of grains/panicle & 0.00048 & 0.06228 \\
Days to maturity (days) & 0.10849 & -0.09063 \\
1000-grain weight (g) & 0.00526 & -0.08509 \\
Grain yield/plot (g) & 0.01875 & -0.00603 \\
\hline
\end{tabular}

In first axis vector-1, all the studied characters having positive impact towards divergence except for days to $50 \%$ flowering and number of panicles $/ \mathrm{m}^{2}$. In vector-2 plant height, days to $50 \%$ flowering, flag leaf length, panicles $/ \mathrm{m}^{2}$, panicle weight, spikelet fertility, number of grains/panicle had positive impact towards divergence. The character that showed positive value in both vectors contributed most towards divergence. That means panicle weight contributed most for divergence in the studied parental lines of hybrid rice.

\section{Conclusion}

The performance and heterosis of hybrids are associated with genetic divergence between their parental lines. Diverse genetic origin between the parental 
lines enhances possibility for maximum heterosis. Selection of parental lines based on diversity will help making promising test hybrid development and upon seed production feasibility, potential rice hybrid will come out for commercial exploitation.

\section{References}

Amirjani, M.R. 2011. Effect of salinity stress on growth, sugar content, pigments and enzyme activity of rice. Int. J. Bot. 7 (1): 73-81

Digby, P.N., Galway and P. Lane. 1989. Genstat 5: A Second Course. Oxford Sci. Publication, Oxford. Pp 103-108.

Faruque, A. 2009. Hybrid seed for food security. Keynote paper in the Bangladesh Seed Conference and Fair 2009 held at Bangladesh China Friendship Conference centre during 28-30 May 2009.

Hossain, M. 1995. Sustaining food security for fragile environments in Asia: Achievements, challenges and implications for rice research. In: Fragile lives in fragile ecosystems. Proceedings International Rice Research Conference, 13-17 Feb 1995, Manila, Philippines. International Rice Research Institute. P. 3-23.

Iftekharuddaula, K M., K. Akter, Bashar and M R. Islam: 2002. Genetic parameters and cluster analysis of panicle traits in irrigated rice. Bangladesh J. Pl.Breed. Genet. 15(1):49-55. Jager, M . I., D. Garethojones and E. Griffith. 1983. Component of partial resistance of wheat seedlings to Septoria nodorum. Euphytica 32: 575-584.

Julfiquar, A. W., S. S. Virmani and A. L. Carpena. 1985. Genetic divergence among some maintainer and restorer lines in relation to hybrid breeding in rice (Oryza sativa L.). Therory of Applied Genetics 70(6): 671-678.

Khush, G. S., 2005. What it will take to feed 5.0 billion rice consumers in 2030. Plant Mol. Biol. 59: 1-6.

Mahalanobis, P.C. 1936. On the Generalized Distance in Statistics. Proc. Natl. Inst. Sci. India, 2: 49-55.

Naik, A. R., D. Chaudhury and J. N. Reddy. 2004. Genetic divergence studies in scented rice. Oryza 40: 79-82.

Roy, B., A. K. Basu and A. B. Mandal. 2002. Genetic diversity in rice (Oryza sativa L.) genotypes under humid tropics of Andaman based on grain yield and seed charecters. Indian Journal of Agricultural Science 72: 84-87.

Sarawgi, A. K. and M. N. Shrivastava. 1996. Genetic divergence in rice under irrigated and rainfed condition. Advances of Plant Science 9: 93-100.

Sarawgi, A. K. and N. K. Rastogi. 2000. Genetic diversity in traditional aromatic rice accessions from Madhya Pradesh. Indian Journal of Plant Genetic Research 13:138-146. 
Singh, R.K. and B.D. Chaudhaury. 1977. Biometrical methods in quantative genetic analysis. Kalyani Publishers, New Delhi. pp. 215-238.

Yuan, L. P. 1998. Hybrid Rice in China: Present Status and Future Vision. Paper presented at BARC in the workshop on Development and Use of Hybrid Rice in Asia. May 1998. Virmani, S.S. and I. Kumar. 2004. Development and use of hybrid rice technology to increase rice productivity in the tropics. Intl. Rice Res. Notes 29(1): 10-19. 